\title{
Factors influencing sustainability of communally-managed water facilities in rural areas of Zimbabwe
}

\author{
T. Kativhu ${ }^{\text {a, }}$, D. Mazvimavi ${ }^{\text {a }}$, D. Tevera ${ }^{\text {b }}$, I. Nhapi ${ }^{\mathrm{c}}$ \\ a Department of Earth Science, University of the Western Cape, Life Science Building, Robert Sobukwe Road, Bellville 7550, Pvt Bag X17, Bellville, 7535 Cape \\ Town, South Africa \\ ${ }^{\mathrm{b}}$ Department of Geography and Environmental Studies, University of the Western Cape, Robert Sobukwe Road, Bellville 7550, Pvt Bag X17, Bellville, 7535 \\ Cape Town, South Africa \\ ${ }^{c}$ Department of Environmental Engineering, Chinhoyi University of Technology, P. Bag 7724, Chinhoyi, Zimbabwe
}

\section{A R T I C L E I N F O}

\section{Article history:}

Received 1 June 2016

Accepted 25 April 2017

Available online 29 April 2017

\section{Keywords:}

Communally-managed

Influencing

Rural water facilities

Sustainability factors

Technical

\begin{abstract}
A B S T R A C T
Sustainability of point water facilities is a major development challenge in many rural settings of developing countries not sparing those in the Sub-Saharan Africa region. This study was done in Zimbabwe to investigate the factors influencing sustainability of rural water supply systems. A total of 399 water points were studied in Nyanga, Chivi and Gwanda districts. Data was collected using a questionnaire, observation checklist and key informant interview guide. Multi-Criteria analysis was used to assess the sustainability of water points and inferential statistical analysis such as Chi square tests and Analysis of Variance (ANOVA) were used to determine if there were significant differences on selected variables across districts and types of lifting devices used in the study area. The thematic approach was used to analyze qualitative data. Results show that most water points were not functional and only $17 \%$ across the districts were found to be sustainable. A fusion of social, technical, financial, environmental and institutional factors was found to be influencing sustainability. On technical factors the ANOVA results show that the type of lifting device fitted at a water point significantly influences sustainability $(\mathrm{F}=37.4, \mathrm{p}<0.01)$. Availability of spare parts at community level was found to be determining the downtime period of different lifting devices in the studied wards. Absence of user committees was found to be central in influencing sustainability as water points that did not have user committees were not sustainable and most of them were not functional during the time of the survey. Active participation by communities at the planning stage of water projects was also found to be critical for sustainability although field results showed passive participation by communities at this critical project stage. Financial factors of adequacy of financial contributions and establishment of operation and maintenance funds were also found to be of great importance in sustaining water supply systems. It is recommended that all factors should be considered when assessing sustainability since they are interrelated.
\end{abstract}

(๑) 2017 Elsevier Ltd. All rights reserved.

\section{Contents}

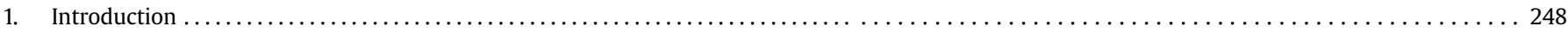

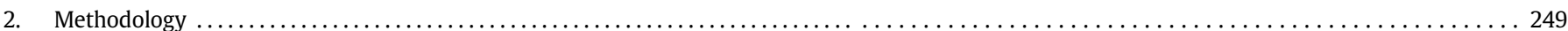

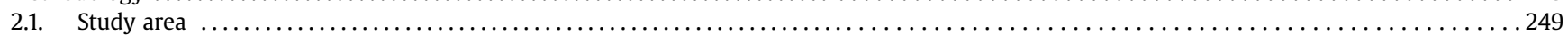

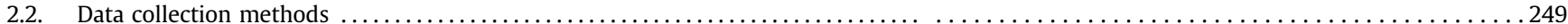

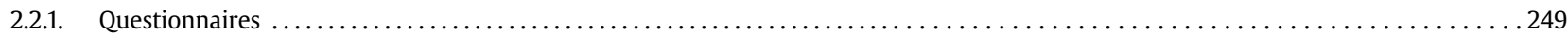

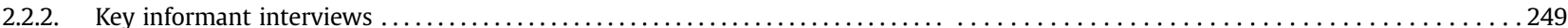

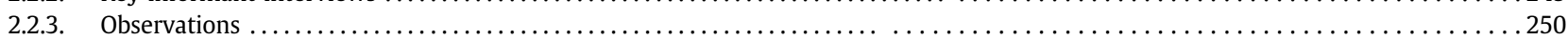

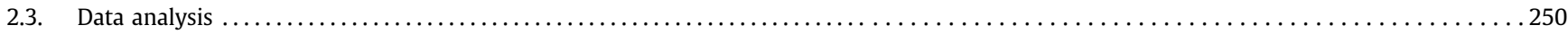

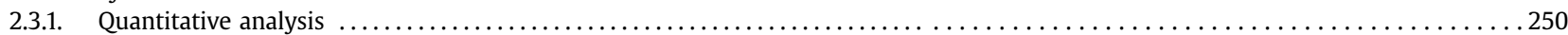

\footnotetext{
* Corresponding author.

E-mail address: tindodemberere@yahoo.com (T. Kativhu).
} 


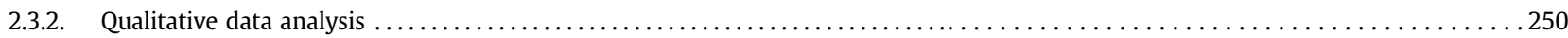

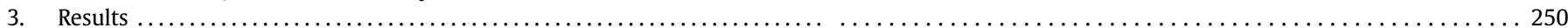

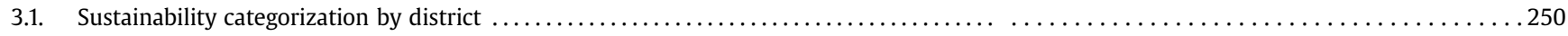

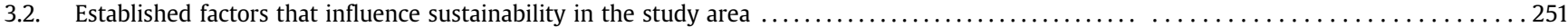

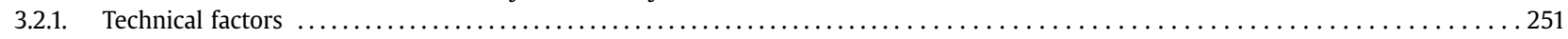

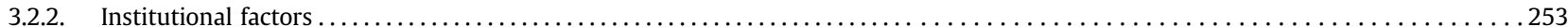

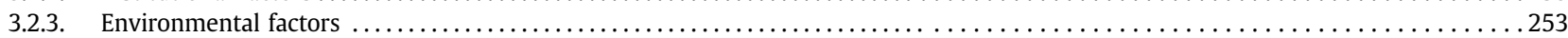

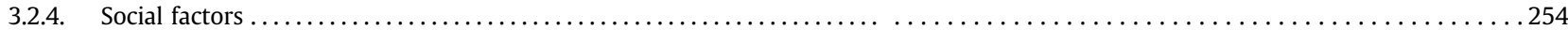

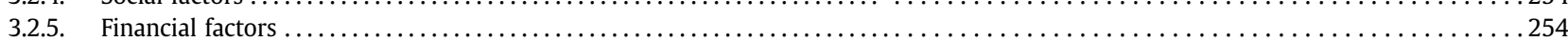

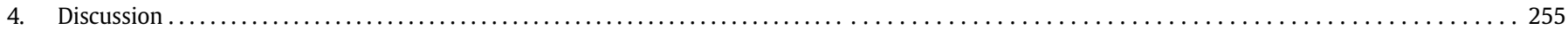

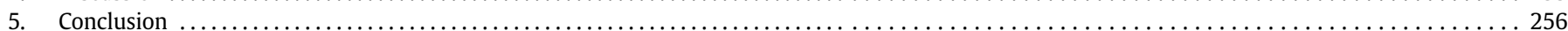

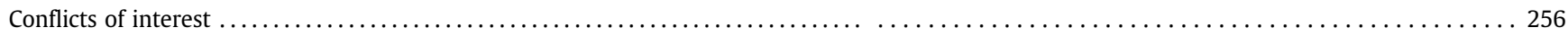

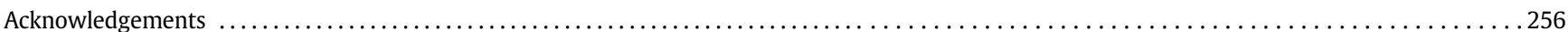

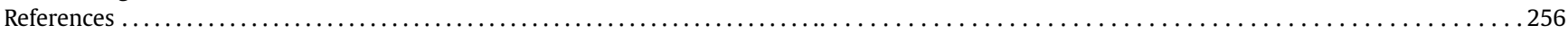

\section{Introduction}

The provision of safe drinking water is a crucial component for the world to eradicate poverty and improve public health. As part of the Millennium Development Goal (MDG) 7, halving the proportion of people without sustainable access to safe drinking water, and basic sanitation by 2015 was one of the targets (United Nations, 2011). Although it was declared that the drinking water part of the goal was met (WHO AND UNICEF, 2014) this is not true globally as some regions still lag behind (WHO AND UNICEF, 2015). Zimbabwe is one of the countries which failed to meet the target on halving the proportion of people without sustainable access to safe drinking water and basic sanitation by 2015. According to WHO AND UNICEF (2015), 77\% of Zimbabwe's population had access to improved water sources in 2015. Notably, the rural areas of the country had $67 \%$ of their population having access to improved water sources (WHO AND UNICEF, 2015). This is a clear indication that, despite the global improvements in water access, Zimbabwe still bears the burden of poor water access.

Despite the disparities in water access, it is also worthwhile to note that the declaration of success ignores two key components of water supply, which are provision of safe water and maintaining sustainable supply systems (Alexander et al., 2015). To meet the drinking water part of the goal, it has been noted that development practitioners in the sector were putting more attention on building new facilities than ensuring their sustainability (Katz and Sarah, 1997; Montgomery et al., 2009). Little investments have been done in operation, maintenance and repairs of the installed infrastructure (Hutton and Bartram, 2008). It has been estimated that only $5-20 \%$ of the total water supply project costs are allocated for Operation and Maintenance (O\&M) against the recommended 60\% for water supply systems to be sustainable (Hutton and Bartram, 2008). Limited or absence of maintenance budgets has compromised sustainability thus depriving communities the benefits of improved water systems. In September 2015, the UN General Assembly developed a stand-alone water goal (number 6), "Ensure the availability and sustainable management of water and sanitation for all" in its Sustainable Development Goals (SDGs) (United Nations, 2011). This development shows that sustainability of water supply systems is still a challenge even after the MDGs.

Numerous studies have shown that sustainability of water supply facilities is a major development challenge in many rural settings of developing countries not sparing those in the SubSaharan Africa region (Harvey and Reed, 2004; Hoko and Hertle, 2006; Tadesse et al., 2013; Spaling et al., 2014; Alexander et al., 2015). In this region non-functional water supply points ranging from $30 \%$ to $70 \%$ have been reported on in the last two decades
(Hoko et al., 2009; Mwnagi and Daniel, 2012; Dube, 2012). In Zimbabwe Hoko et al. (2009) noted that $38 \%$ of the water supply systems were unsustainable in Mt Darwin District, while Dube (2012) observed 60-70\% in Gwanda District. Unsustainable water supply systems usually have long downtimes, high breakdown frequencies, inadequate water supplies, and they are not reliable. These high levels of non-functional water supply systems compromise access to potable water considering that it is a basic human right. This also raises the question why rural water points fail and are abandoned within the very communities that desperately need them (Ihuah and Kakulu, 2014). Therefore there is need to evaluate and put measures for achieving sustainability of the provision of water supply facilities so that the long-term benefits of the investments can be achieved.

Sustainability of water supply services is influenced by a number of factors which have been discussed in numerous rural water supply service discourses. Authors who have discussed these factors include Harvey and Reed (2004), Hoko et al. (2009), Montgomery et al. (2009), Smith (2011), Quin et al. (2011), Peter and Nkambule (2012), Dube (2012), da Silva et al. (2012), Tadesse et al. (2013), Spaling et al. (2014) and Alexander et al. (2015). Broadly, sustainability factors that influence water supply systems have been classified as being economic/financial, social, institutional, technological and environmental (Whittington et al., 2008; Montgomery et al., 2009; Spaling et al., 2014). Different authors have used varying combinations of these factors when assessing sustainability. Those who have considered several factors argue that sustainability is complex and should be assessed in a holistic approach (Carter et al., 1999; Harvey and Reed, 2004; Mays, 2006; Amjad et al., 2015). When Carter et al. (1999) presented these factors as a sustainability chain; they noted that the failure of any one of the links endangers the entire enterprise. On the other hand, Harvey and Reed (2004) presented the sustainability factors as building blocks. The authors emphasized that water facilities will not be sustainable by simply piling these blocks on one another; instead, they must be considered carefully in relation to each other in a holistic approach. da Silva et al. (2012) support the importance of assessing sustainability in a holistic approach since investment in one sustainability factor, for example social capital can enhance other factors such as technical capacity. This shows the importance of integrating all sustainability factors into a multi-faceted approach that recognizes their interrelatedness so that benefits from the water supply facilities are sustained over time (Spaling et al., 2014).

It is against this background that this paper seeks to analyze factors that are influencing sustainability of communally managed water supply facilities in rural areas of Zimbabwe. An 
understanding of such factors at national level will contribute towards achieving the SDGs.

\section{Methodology}

\subsection{Study area}

The study was carried out in three provinces of Zimbabwe. Since the focus of the study was to assess sustainability of communallymanaged water points, purposive sampling was used to select the provinces that had the highest number of communally-managed water supply points (WASH Atlas, 2011). The selected provinces were Manicaland, Matabeleland South and Masvingo. The selection of districts was also purposive where the districts with the highest number of NGOs implementing water projects at the time of the study were selected. The selection was also based on the types of water lifting devices, where the district with all types of water lifting devices used in the province was preferred. Resultantly, Chivi District in Masvingo Province, Nyanga District in Manicaland Province and Gwanda District in Matabeleland Province were selected (Fig. 1).

Stratified random sampling was used to select wards within the study districts. A total of four wards were selected in each district. The districts were stratified according to constituencies. Chivi and
Gwanda districts have three constituencies while Nyanga has two. At least one ward was randomly selected in each constituency in the three districts.

\subsection{Data collection methods}

\subsubsection{Questionnaires}

A total of 399 questionnaires were administered to Water Point Committees (WPCs) in 12 wards selected for this study. The information required was related to the technical, social, economic, financial and institutional performance of the water points. Under each factor several sub-factors/variables were considered.

\subsubsection{Key informant interviews}

Purposive sampling was used to select key informants. These were drawn from Non Governmental Organizations (NGOs) implementing water supply projects, government departments, and community leaders. Six interviews were conducted in each ward while eight interview sessions were conducted at district level in each district. The researcher used both the unstructured and semi-structured interviews. These were used as they are flexible, allowing the researcher to pursue issues as they arise. They also enabled the researcher to probe and follow up on issues which would have risen during the course of the interviews.

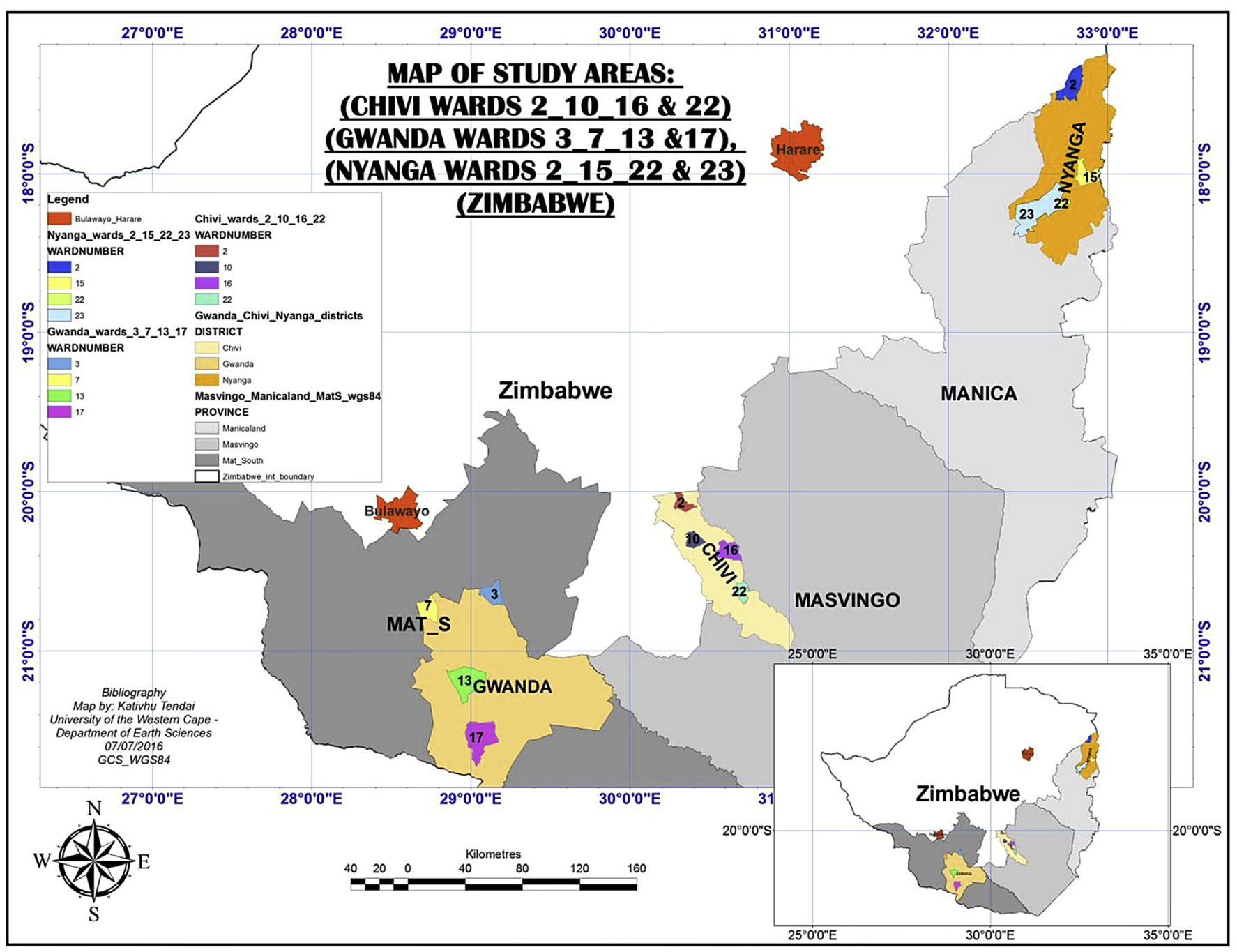

Fig. 1. The location of study areas in Gwanda, Chivi, and Nyanga districts in Zimbabwe. 


\subsubsection{Observations}

During this study observations using an observation checklist were done. Observations were used to triangulate information given by respondents in the questionnaires and during interviews.

\subsection{Data analysis}

\subsubsection{Quantitative analysis}

Statistical Package for Social Sciences (SPSS) version 22 was used to analyze quantitative data.

2.3.1.1. Descriptive statistics. Descriptive statistics on mean, minimum, maximum and standard deviation were generated. Inferential statistical analysis such as Chi square tests and Analysis of Variance (ANOVA) were used to determine if there were significant differences on selected variables across districts and types of lifting devices used in the study area. A p value of $\leq 0.05$ was taken as statistically significant. Descriptive statistics also provided a concise summary of data on various sustainability factors across the three districts under study.

\subsubsection{Multi-Criteria analysis (MCA). Multi Criteria Analysis (MCA)} was used to assess sustainability of water points (Panthie and Bhattarie, 2008). To determine weights for the different sustainability factors for this study the Analytic Hierarchy Process (AHP) method was used. AHP uses hierarchical structures to represent a problem and makes judgments based on experts to derive priority scales (Saaty, 1980). In this study, field experts at district level compared the different factors in terms of how important they are in influencing sustainability. Pairwise comparisons were done between sustainability factors which are environmental, financial, technical, social and institutional. For example, the environmental factor was first compared against the technical factor, secondly against the financial factor, thirdly against the social factor and lastly the institutional factor. The comparisons were later done between all the sub-factors which are presented in Table 1. These factors and sub-factors were derived from literature on rural water supply and they were found to be the most recurring ones.

Within every hierarchal comparison matrix, the experts had to compare each competing alternative against every other competing alternative employing a scale of relative importance (Saaty, 2008). This type of comparison was executed for each factor and sub-factor

Table 1

Factors and sub-factors used in the AHP.

\begin{tabular}{ll}
\hline Factors & Sub-factors \\
\hline Technical & Availability of spare parts \\
& Affordability of spare parts \\
& Functionality \\
& Water point status \\
Social & Community participation in planning \\
& Community participation in O\&M \\
& Proportion of men and women in WPC \\
& Conflict management \\
Institutional & Existence of committees \\
& Functionality of committees \\
& Training in CBM \\
& Level of external support \\
& Availability of rules \\
Financial & Presence of O\&M fund \\
& Frequency of making financial contributions \\
& Transparency on use of funds \\
& Presence of rules on fee collection \\
& Reliability of water supply \\
Environmental & Water quality at source \\
& Potential for contamination \\
\hline
\end{tabular}

and this allowed the construction of judgment matrices for the factors and sub-factors. The judgment matrices had the dimensions, MxM, where " $\mathrm{M}$ " is the total number of alternatives considered. In this study, the judgement matrix for sustainability factors was equal to five $(5 \times 5)$. The dimensions of the matrices for sub-factors were determined by the number of sub-factors under each factor.

During performance scoring, several questions were asked to WPCs and water users to assess the field performance of each subfactor. Data were assigned scores using the methodology developed by (Kaliba, 2002). The methodology is based upon the principle that 1 represents a positive contribution towards a sub-factor and 0 represents no contribution. The methodology was adopted since it is suitable for the assessment of the sustainability of rural water supply systems (Peter and Nkambule, 2012). The methodology by Kaliba also enables the quantification of performance by water supply systems. Sara and Katz (2005) also used similar techniques based on primary data collected using a structured questionnaire. In their study for each question asked, a score was given for each response as follows; if the response contributed positively towards sustainability, the response scored $a+2$. If the response did not contribute positively, it was given a score of 0 . If the response indicated neither positive nor negative performance, it scored $a+1$. The responses were then aggregated at the project level as indices of sustainability.

The weight of each factor which was assigned through the AHP was then multiplied by the factor's performance score obtained in the field to get the sustainability score of that factor. The summation of the sustainability scores for all the factors then gave the overall sustainability score of an individual water point so that it was classified as highly sustainable, sustainable, partially sustainable or not sustainable as shown in Table 2.

All the water points were then classified according to their sustainability scores.

\subsubsection{Qualitative data analysis}

The thematic approach was used in the analysis of qualitative data. Themes in this paper were from both the field data (an inductive approach), and from the researcher's prior theoretical understanding of the phenomenon under study (deductive approach). Reading through the field notes enabled the researcher to code the data. Coding is when data sets were labeled into categories based on the research objectives. After coding, data was then grouped into themes. For example, all information related to financial factors of sustainability such as presence of an O\&M fund, regularity of making financial contributions, adequacy of funds and rules on fee collection formed one theme. This was done for all the other factors of sustainability which were presented in Table 1.

\section{Results}

\subsection{Sustainability categorization by district}

Table 2 was used to establish sustainability categories. The overall sustainability scores per district were the mean scores of all the water points studied in that district. Based on this classification,

Table 2

Sustainability classification of water points.

\begin{tabular}{lll}
\hline Classification & Range of measurement & Sustainability category \\
\hline Very Good & $75-100 \%$ & Highly sustainable (HS) \\
Good & $50-74 \%$ & Sustainable (S) \\
Fair & $25-49 \%$ & Partially sustainable (PS) \\
Poor & Below 25\% & Not Sustainable (NS) \\
\hline
\end{tabular}


$33 \%$ of the water points were in the partially sustainable and not sustainable categories. Notably, Gwanda District had the highest proportion (74\%) of water points which were sustainable and highly sustainable. On the other hand, Nyanga District recorded the highest proportion of water points which were partially sustainable and not sustainable (48\%). In Chivi District, $37 \%$ of the water points were partially sustainable and not sustainable (Fig. 2).

Chi square test results show that sustainability of water points differed significantly across the three districts $\left(\chi^{2}=73.59\right.$, $\mathrm{df}=4$, $\mathrm{p}<0.01)$. These differences exist because factors which affect sustainability are context-specific, and this is what the literature on factors of sustainability suggests. Sustainability classes were also not uniform across the wards in the three districts (Table 3 ).

Most (66\%) of the wards were in the sustainable category. Chivi and Nyanga districts had one ward each in the not sustainable class, while Gwanda District did not have a ward in the class. Instead, Gwanda District was the only district with two wards in the highly sustainable class. Of importance to note is that, the wards which were in the partially sustainable class had low scores (36 and 31.1\%) which may likely drop into the not sustainable category. The differences in sustainability performance within districts were attributed to the presence of NGOs in certain wards within a district. Wards which had NGOs operating in them tend to perform better in institutional and technical factors than those which did not have.

\subsection{Established factors that influence sustainability in the study area}

The factors of sustainability which were studied are technical, social, institutional, environmental and financial. These factors are discussed in the following sections.

\subsubsection{Technical factors}

3.2.1.1. Type of lifting device used. Types of lifting devices used in the study area are Bush Pumps (BPs), Elephant Pumps (EPs), Rower Pumps (RPs) and Windlass. These are shown in Fig. 3.

These lifting devices had varying overall sustainability scores across the districts. The mean values of these scores ranged between 48.03 for elephant pumps and 75.30 for the rower pumps (Table 4).

The ANOVA results show that there is a significant difference in the mean overall scores of sustainability for each lifting device. This result indicates that the type of water lifting device significantly
Table 3

Sustainability scores and classification per ward.

\begin{tabular}{llll}
\hline District name & Ward number & Ward average score (\%) & Sustainability classify \\
\hline Nyanga & 2 & 31.1 & Partially Sustainable \\
& 15 & 20.7 & Not Sustainable \\
& 22 & 54.7 & Sustainable \\
Gwanda & 23 & 62.4 & Sustainable \\
& 3 & 58.0 & Sustainable \\
& 7 & 76.9 & Highly Sustainable \\
& 13 & 75 & Highly Sustainable \\
Chivi & 17 & 61.6 & Sustainable \\
& 2 & 72 & Sustainable \\
& 10 & 36 & Partially Sustainable \\
& 16 & 58.5 & Sustainable \\
& 22 & 21.4 & Not Sustainable \\
\hline
\end{tabular}

influences sustainability ( $\mathrm{F}=37.4, \mathrm{p}<0.01)$.

The distribution of the lifting devices among the sustainability categories is shown in Fig. 4.

Sustainability classification by water lifting device was done since mean sustainability scores did not give a full picture on how lifting devices were distributed among the different sustainability categories. Results show that bush pumps, windlass and elephant pumps recorded water points in all the four sustainability categories while the rower pump had its water points distributed in the highly sustainable, sustainable and partially sustainable categories. These results show that, the rower pump is the most viable water lifting device in achieving sustainability with no pumps recorded in the not sustainable category. The lifting device had $80 \%$ of its water points in the sustainable and highly sustainable classes indicating its impact on promoting sustainability. The least sustainable water lifting device was the elephant pump which dominated (75\%) in the partially sustainable and not sustainable categories. Bush pumps which are the most common water lifting device in the study area recorded $52 \%$ partially sustainable and not sustainable water points. The distribution pattern in Fig. 4 shows that, sustainability is a challenge in the study area as most water points across the lifting devices are dominating the not sustainable and partially sustainable categories. Statistically, sustainability differed significantly with type of water lifting device $\left(\chi^{2}=90.48, \mathrm{df}=8, \mathrm{p}<0.01\right)$. Although the type of lifting device does not influence sustainability alone, it is an important explanatory variable.

3.2.1.2. Functionality of water points. Results show that across the three districts, $41 \%$ of the water points were not functioning.

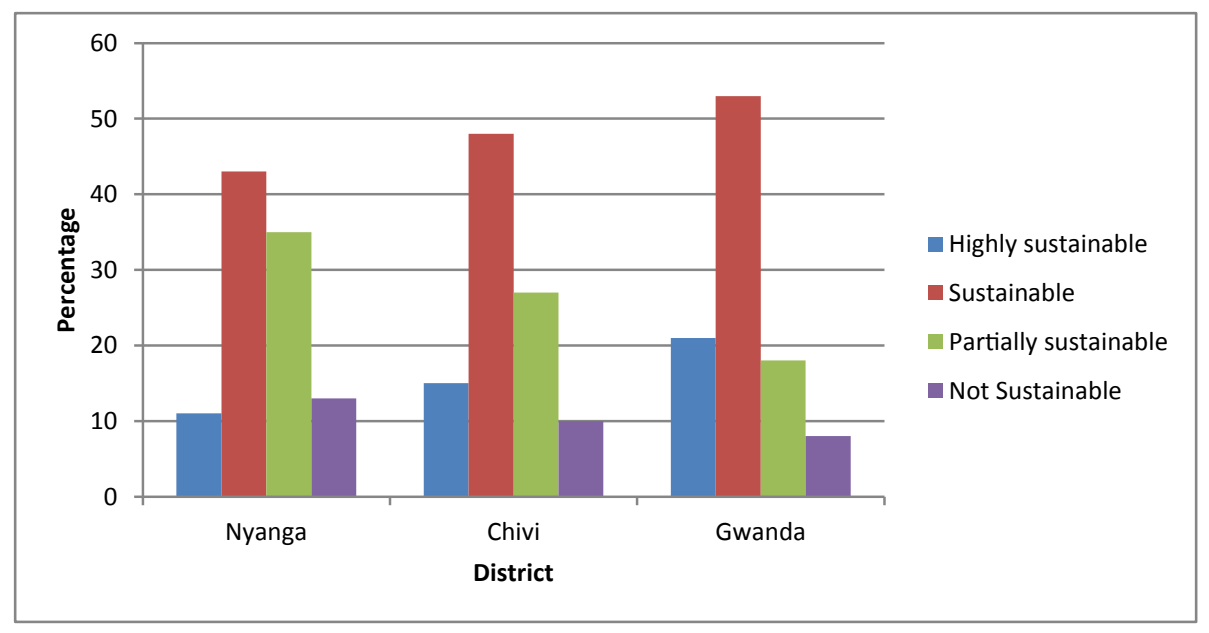

Fig. 2. Sustainability classification by district. 

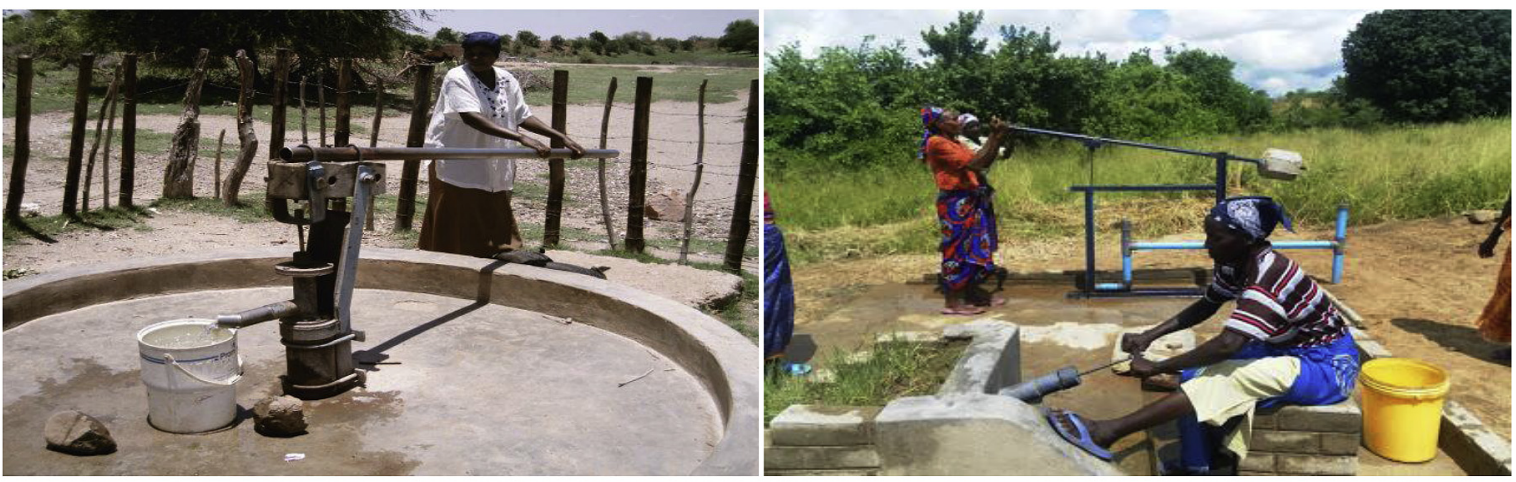

Bush Pump

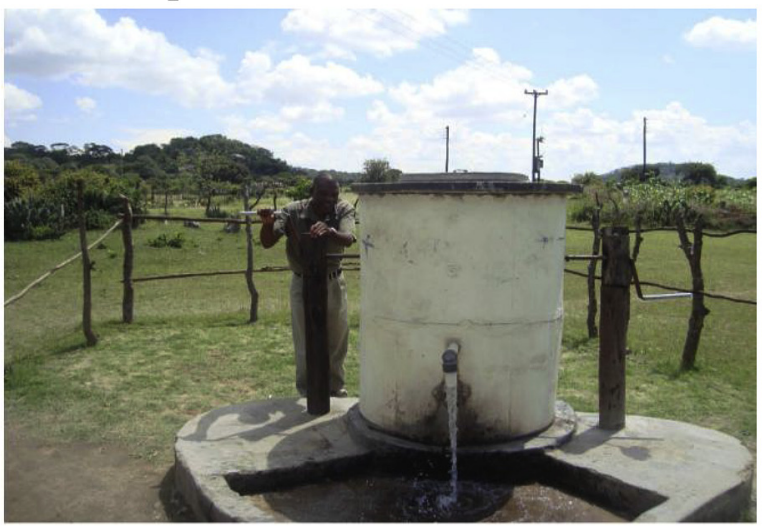

Rowa Pump

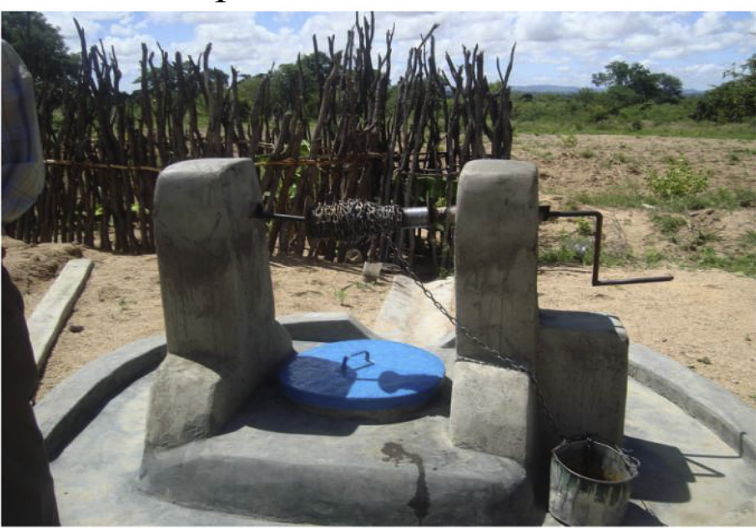

Elephant Pump

\section{Windlass}

Fig. 3. Types of lifting devices used in the study area.

Table 4

Mean sustainability scores (\%) by water lifting devices used in the study districts in 2015.

\begin{tabular}{llll}
\hline Lifting device & Mean & $\mathrm{N}$ & Std. Deviation \\
\hline Bush pumps & 57.96 & 291 & 15.264 \\
Elephant pumps & 48.03 & 32 & 12.060 \\
Rower pumps & 75.30 & 57 & 13.587 \\
Windlass & 66.39 & 19 & 13.840 \\
Total & 61.67 & 399 & 18.165 \\
\hline
\end{tabular}

Nyanga district recorded the highest percentage (43\%) of nonfunctional water points while Chivi and Gwanda recorded $40 \%$. High non-functional water points negatively impact on water availability for domestic use. The chi square test results $\left(\chi^{2}=0.277\right.$, $\mathrm{df}=2, \mathrm{p}=0.871$ ) show that functionality did not vary significantly in all the districts. However, further statistical analysis showed that functionality differed significantly with type of lifting device $\left(\chi^{2}=0.654, \mathrm{df}=2, \mathrm{p}<0.01\right)$. Elephant pumps had the highest percentage (59\%) of non-functional water points while bush pumps

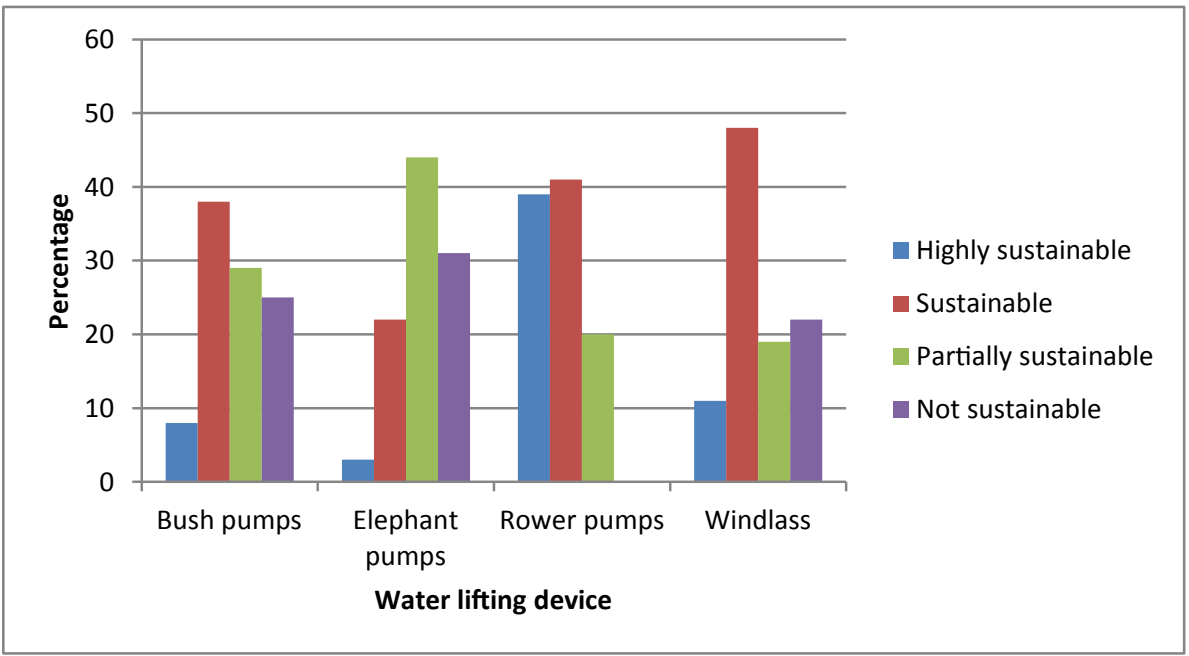

Fig. 4. Sustainability classification by water lifting device. 
had $32 \%$ and rower pumps had $11 \%$. Differences in functionality across water lifting devices were attributed to the unavailability of spare parts at local level and the cost of repairing the lifting devices in question.

The average downtime of water points ranged from days to more than six months. Most water points in all the districts had an average downtime of 2 months (Gwanda $=30.5 \%$, Chivi $=38.3 \%$ and Nyanga $=35.7 \%$ ) which is above the 2 days downtime required for sustainable water points (Dayal et al., 2000). Elephant pumps were noted to be the lifting device that took long to be repaired after a breakdown. Most elephant pumps (42\%) had a downtime period of over 6 months. The main reasons cited for long down time periods for elephant pumps were the unavailability of spare parts at local level and inadequate water supply at water points fitted with the technology. Long downtime periods resulted in some water points being vandalized were it was reported in $16 \%$ of the studied cases. Results show that six elephant pumps which were vandalized ended up being neglected as communities cited high repair costs since major parts were stolen. The lifting device that had an average downtime of days was the rower pump. The availability of spare parts for the rower pump at community level was noted to be the major contributory factor to the shorter downtimes as compared to the other lifting devices. The Chi square test results $\left(\chi^{2}=134.6, \mathrm{df}=16, \mathrm{p}<0.01\right)$ show that down time varies significantly across the districts. Downtime periods were also statistically different across lifting devices with chi square test results being $\left(\chi^{2}=113.2, \mathrm{df}=15, \mathrm{p}<0.01\right)$.

3.2.1.3. Spare parts availability. Respondents indicated that spare parts for bush pumps were not available at community level in all the three districts. However, spare parts were available at district level from the District Development Fund (DDF), a government technical department in the rural water sector. According to the DDF personnel interviewed, spare parts found at their district offices were those donated by NGOs hence the type and quantity of spares available depended on the nature of NGO projects implemented in their districts. On the other hand, spare parts for elephant pumps were unavailable from both the DDF district offices and local markets in Chivi. Communities complained that they buy the spare parts from private dealers from the provincial town of Masvingo, who sometimes supply sub-standard parts which resulted in frequent breakdowns. This was contributing to high unsustainable water points fitted with hush pumps and elephant pumps. Spare parts for rower pumps were found to be readily available at community level. The spares are manufactured locally by Dabane Trust a local NGO operating in Gwanda District. The organization has Field Officers who are found at ward level. These Field Officers help in purchasing spares for communities from Dabane Trust offices. This could explain why the rower pumps had an exceptional mean sustainability score of $75.30 \%$ which is in the highly sustainable category while other lifting devices were in the sustainable and partially sustainable categories (Table 4).

\subsubsection{Institutional factors}

3.2.2.1. Existence of water user committees. User committees which were found to be present at water point level are Water Point Committees (WPCs) and Maintenance Committees (MCs). WPCs are the highest management committee at community level while MCs consist of water point users trained for basic maintenance of a water point. Of all the water points that were studied, only $13.3 \%$ had maintenance committees. Chivi District had the highest proportion (26\%) of water points with maintenance committees, while Nyanga District recorded no water points with maintenance committees. Water point users with functional maintenance committees attributed reliability of their water points to the functionality and active participation of maintenance committee members. Where maintenance committees were absent, communities cited long down time periods (averaging 2 months). The chi square test results $\left(\chi^{2}=31.02, \mathrm{df}=2, \mathrm{p}<0.01\right)$ show that the existence of maintenance committees varies significantly in all the districts.

WPCs were found to be the most common user committees at water point level (Gwanda 98\%, Chivi 97\%, Nyanga 92\%). However, it was noted that the existence of WPCs did not guarantee their functionality as $91 \%$ were found to be functional in Gwanda, while Chivi had $86 \%$ and Nyanga had $80 \%$. Results show that water points with WPCs had an overall sustainability score of $67.4 \%$ (sustainable category) while those without WPCs had a score of $20.8 \%$ (not sustainable category). This shows the importance of WPCs in influencing sustainability of water supply systems as argued by Harvey and Reed (2004). Communities cited poor coordination in collecting money for O\&M in the absence of WPCs. The chi square test results $\left(\chi^{2}=138.02, \mathrm{df}=8, \mathrm{p}<0.105\right)$ show that there is no significant difference in the existence of WPCs across districts.

3.2.2.2. Training in community-based management (CBM). Where user committees are put in place they need to be equipped with technical and managerial skills through CBM trainings (Quin et al., 2011). The percentage of WPCs that received training in CBM was $52.3 \%$ for Chivi, $47.2 \%$ for Gwanda and 38.3\% for Nyanga. Key informants indicated that in the last ten years, no CBM trainings have been facilitated by the government in their districts. All trainings were being facilitated by NGOs. This saw WPCs of water points which will not have been selected in NGO projects being excluded from trainings. Communities attributed poor managerial and technical performance of WPCs to absence and inadequate trainings in CBM. This was seen to be negatively influencing sustainability in the three districts. The chi square test results $\left(\chi^{2}=4.54, \mathrm{df}=2, \mathrm{p}=0.103\right)$ show that there was no significant difference in CBM trainings across the districts.

3.2.2.3. External support. The provision of external support by institutions at district and national level to local communities is indispensable for sustainability to be achieved (WaterAid, 2011). Results show that communities receive training, monitoring of water point performance, repair of major breakdowns and spare parts from institutions at district level. The institutions that were providing external support were the DDF and NGOs. However, it was noted that when there is a major breakdown communities are expected to contribute money for fuel for the DDF technical team to attend to the breakdown. This practice resulted in some breakdowns taking long to be attended to. As for the supply of spare parts it was noted that the availability of spare parts depended on the nature of projects being implemented by NGOs as they were the source of the spare parts. Monitoring of water point performance by the DDF team was said to be infrequent as compared to that by NGOs. However, NGOs were reported to be monitoring water points they would have drilled or rehabilitated under their projects. Water points that received external support in the form of training were those water points that would have been selected in certain NGO projects as training was mainly facilitated by such organizations. This automatically excluded water points which will not be part of the projects. Gwanda District had the highest percentage (60.8\%) of water points that have received external support from institutions at district level while Chivi had the least percentage (53.9\%). The chi square test results $\left(\chi^{2}=6.47, \mathrm{df}=6, \mathrm{p}=0.312\right)$ show that there was no significant difference in water points that have received external support across the three districts.

\subsubsection{Environmental factors}

3.2.3.1. Water quality at source. Water quality at source was 
assessed using user perceptions on smell, color and taste of the water. User perception on water quality is of great importance on sustainability of water supply systems as users may neglect a water point if it is perceived to be providing water of a bad quality. Responses on water quality were categorized as bad, good and excellent. Generally smell and color of water were considered to be of good quality across the three districts. However, respondents complained of boreholes which supplied water with a salty taste in $32 \%$ of the cases in Chivi, $27 \%$ in Gwanda and 14\% in Nyanga districts. Water from the salty boreholes was also associated with high soap consumption. Communities were not willing to make financial contributions for repairs of such water points resulting in long downtimes. An example was noted in Ward 16 of Chivi District where a water point fitted with a bush pump was neglected as the water it supplies was considered to be salty. In some cases it was reported that communities were no longer using the considered salty water points for domestic purposes but for watering livestock. However, further analysis show that some salty water points were neglected only during the rainy season when communities will be having alternative water sources such as shallow wells which were considered to be supplying water which was perceived not to be salty. During the dry season, communities would go back to the salty water points as they will be the only available water points. This resulted in such water points not being maintained and repaired during the rainy season.

3.2.3.2. Adequacy of water supply. The amount of water collected was considered inadequate by $62 \%$ of the respondents. Most water points under study (55\%) were not able to supply water all year round. A high percentage (97\%) of shallow wells installed with elephant pumps was not supplying water all year round. Sand abstraction sites installed with rower pumps had the lowest percentage (37\%) of water points that do not supply water all year round. High percentages of water points which do not supply water all year round compelled almost $36 \%$ of the studied households to depend on unprotected water sources which were a remedy to long distances travelled to nearby protected water sources. The impact of inadequate water supply on sustainability was twofold. Firstly, communities were not keen to repair a water point when it breaks down towards its expected time of drying up hence long down time periods. Secondly, where communities had to use water points in nearby villages as alternative water sources, this put pressure on the existing water points which resulted in frequent breakdowns thereby negatively influencing sustainability. The chi square test results $\left(\chi^{2}=1.105, \mathrm{df}=2, \mathrm{p}=0.576\right)$ show that there is no significant difference in water points that supply water all year round across districts.

\subsubsection{Social factors}

3.2.4.1. Community participation in planning. Communities participated during the planning stage of their water supply projects as $79 \%$ of the respondents indicated their participation. In Chivi District, $86 \%$ participated at the planning stage while in Nyanga and Gwanda districts 78\% and 76\% participated, respectively. The forms of participation and the proportion of respondents who participated during the planning stage are presented in Table 5.

Table 5 shows non-participation of communities in decision making about critical issues on a water project. This type of participation is known as "tokenistic" or "passive" participation (Manikutty, 1997). In the study area, although respondents knew about the projects before they were implemented, they never participated in needs assessment. Households neither decided whether they wanted the projects or not, nor selected their preferred type of technology. It was learnt that the technologies implemented were the choice of the donors. A total of $72 \%$ of the respondents in Chivi District indicated that if they were consulted on their preferred type of lifting device, they preferred the windlass over the elephant pumps. The reasons which were cited are that, elephant pumps were more expensive to maintain than the windlass, and the spare parts for elephant pumps were not available at community level. Furthermore, it was noted that VPMs did not have the adequate skills to repair elephant pumps while the windlass did not require skilled personnel. These results explain why elephant pumps had long downtimes hence their dominance in the partially sustainable and not sustainable categories.

3.2.4.2. Community participation in operation and maintenance $(O \& M)$. All the interviewed households indicated that they have been participating in operation and maintenance of water points. Most households (92\%) indicated that they have been contributing cash for maintenance. In some instances (41\%) communities contribute grain, small livestock, labor and/or locally available material during repair or rehabilitation of the water points. Some respondents also indicated that they have been involved in setting rules for fee collection as well as setting tariffs to be collected. User communities especially women who are the main water collectors at household level were also involved in monitoring water point performance. Monitoring was said to be done all the time someone visits a water point and the monitoring results were reported to the WPCs, Village Health Workers (VHWs) or village heads. Participation of user communities in operation and maintenance is indispensable for sustainability of rural water supply systems to be achieved (Harvey and Reed, 2004). Participation at this project stage is expected to reduce down times due to immediate responses by user communities.

\subsubsection{Financial factors}

An O\&M fund was found at $24.8 \%$ of the water points in the three districts. Nyanga had $10 \%$ water points with an O\&M fund while Chivi had 14\% and Gwanda (40.7\%). O\&M fund is of crucial importance for the maintenance of water points (Schouten and Moriarty, 2003; Harvey and Reed, 2006). However, O\&M funds which were found at most water points were not adequate to cover costs of repairing a water point after a break down. The funds ranged from as little as $\$ 1$ to $\$ 30$ across the three districts. Considering that the spare parts for bush pumps and elephant pumps were not available at community level, these funds were too little to cover transport costs, costs of buying spare parts and to pay

Table 5

The forms of participation and the percentages of households who participated during the planning stage per district.

\begin{tabular}{|c|c|c|c|}
\hline Form of participation & Chivi (\%) & Gwanda (\%) & Nyanga (\%) \\
\hline Households aware of the water project before construction & 56 & 60 & 45 \\
\hline Households attending meetings before water project was constructed & 66 & 78 & 62 \\
\hline Households who participated in needs assessment & 0 & 0 & 0 \\
\hline Households involved in decision making about type of technology to be used & 0 & 0 & 0 \\
\hline Households involved in decision making on whether communities want the project or when the project should be implemented & 0 & 0 & 0 \\
\hline Households involved in decision making about the site of water points & 7 & 6 & 9 \\
\hline
\end{tabular}


village pump mechanics. Pump mechanics across the three districts charged an average of $\$ 70$ per repair, making an average cost to repair a pump to be between $\$ 80$ and $\$ 100$ which is more than three times the highest amount found in the O\&M funds.

WPCs cited poverty as the major factor contributing to inadequacy of funds contributed towards O\&M. Households in the studied districts had little monthly income (average \$38) which was shared among a number of activities such as purchasing food, paying school fees, paying medical costs and buying agricultural inputs. It was noted that priority was given to the other expenditures as they were considered to be more pressing than contributing towards O\&M. Communities preferred to make financial contributions towards O\&M after a break down. Contributions after a breakdown were preferred as communities will be seeing the need and urgency to pay for the repair of a water point. Frequencies of making financial contributions are shown in Table 6 .

Gwanda had (26\%) WPCs which collected financial contributions for O\&M monthly while Chivi had $11 \%$ and Nyanga had $6 \%$. Irregularity in making financial contributions resulted in long down times; hence negatively influencing sustainability. Water points which were supporting livelihood activities such as community gardening had WPCs that collected financial contributions on monthly basis across the districts. Users of such water points cited that long downtimes affect their garden crops; therefore the presence of O\&M funds facilitated immediate repairs of their water points. Members of the community gardens also reported that they can afford to make monthly financial contributions towards O\&M through selling their garden produce.

\section{Discussion}

The study investigated factors influencing sustainability of communally-managed water supply systems in rural areas of Zimbabwe. The factors found were broadly categorized into institutional, technical, social, environmental and financial. From the results, it is notable that $33 \%$ of the studied water points were not sustainable according to the author's classification discussed in Chapter three. Some of the water points in the sustainable category had low sustainability scores which may likely drop into the partially sustainable range. The high proportion of unsustainable water points is what the literature on rural water supply would suggest to be the case for developing countries. In the sub-Saharan Africa region, unsustainable water points of between 20 and $40 \%$ have been reported on (Harvey and Reed, 2004; Peter and Nkambule, 2012). At national level these results are not unique as studies by Hoko et al. (2009) and Dube (2012) also showed high levels $(38-70 \%)$ of unsustainable water points in some parts of Mt Darwin and Gwanda districts. This implies that, although governments of developing countries may continue to invest in the implementation of physical infrastructure, communities may not enjoy the intended benefits of the investments if sustainability problems are not solved. Thus, for such investments to positively contribute towards the achievement of the SDGs in the rural water supply sector, the underlying factors of sustainability should be known since the provision of improved water points is not enough if the facilities are not sustained.

Table 6

Frequency of making financial contributions for O\&M in the study districts in 2015.

\begin{tabular}{llll}
\hline District & After a breakdown (\%) & Monthly (\%) & Not done at all (\%) \\
\hline Gwanda & 70 & 26 & 4 \\
Chivi & 86 & 11 & 3 \\
Nyanga & 82 & 6 & 12 \\
\hline
\end{tabular}

On technical factors there was evidence that lifting devices significantly influence sustainability. The ANOVA results show that there is a significant difference in the mean overall scores of sustainability for each lifting device. These differences could be as a result of absence of technical external support in Chivi district on spare parts supply while in Gwanda District spare parts of the rower pump were found at community level with the assistance of a local NGO. The importance of technical external support through effective spare parts supply chains have been emphasized in the rural water supply sector (Schouten and Moriarty, 2003). Results on functionality show that $41 \%$ of the water points were not functioning. These results are consistent with the theoretical expectations as literature has shown that at any given time $30-70 \%$ of rural water supply systems are not functioning in the sub-Saharan Africa region (Harvey and Reed, 2004; Mwnagi and Daniel, 2012; Dube, 2012). Further analysis show that functionality differed significantly with type of lifting device $\left(\chi^{2}=0.654, \mathrm{df}=2, \mathrm{p}<0.01\right)$. The lifting device (rower pump) which had a low proportion of nonfunctional water points had also the highest sustainable water points. This suggests that where a water point will be functioning other factors of sustainability such as institutional, social and financial will be in place as was evidenced by the survey results. The lifting device (elephant pump) which had the highest proportion (59\%) of non-functional water points was also found to be performing badly in other sustainability factors hence its low (48.03\%) average sustainability scores. This result clearly shows the interlinkages that exist among sustainability factors. Such relationships need to be known to enhance the overall sustainability of water supply systems.

Water points that were functional and were in the highly sustainable and sustainable categories had functional WPCs and MCs, while most of the unsustainable water points did not have functional committees. This implies that, sustainability is threatened by the non-functionality of user committees. These results resonate with findings by Marks et al. (2013) when they concluded that, communities which had user committees had more sustainable water supply systems than those who did not have such committees in Ghana. Other scholars who emphasized on the importance of functional user committees in promoting sustainability are Harvey (2008) and Whittington et al. (2008). However, results showed that such committees need to be capacitated in conflict management, managerial, technical and financial skills through CBM training for sustainability to be enhanced. The low percentages of trained WPC in CBM in the study area had a negative impact on other factors of sustainability such as technical, financial and social factors. Such inter-linkages show the need of addressing sustainability in a holistic manner since an investment or a weakness in one factor may influence the other factors.

Communities were not given a chance to make decisions on the type of project and or technology they want during the planning stage. These results explain why elephant pumps had long downtimes hence their dominance in the partially sustainable and not sustainable categories. This is consistent with the majority of published empirical studies on participation, where non-utilization of local knowledge at the needs assessment stage led to low sustainability of water systems considering different community preferences (Manikutty, 1997; Prokopy, 2005). U-Dominic et al. (2015) concluded that non-participation of communities in technology selection resulted in inappropriate technologies being installed in Anambra State in Nigeria. This supports the general conception that community participation in decision making leads to projects that are better designed to meet the unique needs of each community (Prokopy, 2005). User communities should be given a chance to select technologies they are able and willing to operate and maintain to promote sustainability. However, this can 
only be achieved through active community participation during the planning stage.

The existence of an O\&M fund and the adequacy of financial contributions are critical for sustainability of water supply systems. This is in line with results from other studies (Baumann and Danert, 2008; Giné and Pérez-Foguet, 2008). However, it was noted that irregularity of contributions was negatively impacting on the adequacy of funds which resulted in long downtimes of water points. Prokopy (2005) also found similar results where sustainability of water points was negatively influenced by inadequacy of $O \& M$ funds in India. In the same regard, Haysom (2006) also found out that water points which were contributing inadequate funds for O\&M were not sustainable in Tanzania. The prevailing harsh economic conditions in Zimbabwe seemed not to spare the rural water supply sector. The communities which are supposed to fund the O\&M of water systems had an average monthly income of $\$ 38$ which is well below the Poverty Datum Line of $\$ 481$ (ZimStat, 2016). This has resulted in communities making infrequent and inadequate contributions towards O\&M. These results are similar to conclusions by Dube (2012) who found out that communities in Gwanda District of Zimbabwe were failing to make financial contributions due to high poverty levels. In such cases were communities survive in deep poverty, other financing mechanisms need to be considered. The government may need to subsidize spare parts so that they are affordable for sustainability to be achieved.

Results on environmental factors show that water points which were perceived to be supplying water with a salty taste were neglected in Chivi District. These results agree with Hoko et al. (2009) when they concluded that salty water points in the Mt Darwin District of Zimbabwe were neglected and not repaired as communities used river beds and shallow wells as alternative water sources. Notably chance of contamination was considered not to be of importance in influencing sustainability across the districts. This shows that, perceived physical water quality had a negative impact on sustainability than the biological quality despite the public health threats which are associated with water of poor biological quality. In such cases health education and provision of equipment for water treatment at household level becomes an imperative component for rural water supply projects.

\section{Conclusion}

This paper has shown that a combination of institutional, technical, social, financial and environmental factors influenced the sustainability status of water points. Technical factors which were found to be influencing sustainability are type of lifting device, functionality of the water point and availability of spare parts. These technical factors were found to be related to the institutional factor of level of external support where the role of institutions at district and national level of providing effective supply chains was found to be critical. Institutional factors on existence and functionality of water user committees were also found to be central in the sustainability of water supply systems. However, it was concluded that, the user committees have to be provided with appropriate and adequate technical, financial and managerial skills and support for sustainability to be enhanced. It was also noted that generally the financial performance of most water points was poor which had a negative influence on sustainability. Nevertheless the use of some water points for watering nutrition gardens seemed to provide a solution as communities were selling their produce to maintain their water points. Scaling up the multiple uses of water points to support livelihood activities may enhance sustainability of water supply systems.

\section{Conflicts of interest}

There is no conflict of interest.

\section{Acknowledgements}

The authors are grateful for data collection funding from Schlumberger Foundation Faculty of the Future.

\section{References}

Alexander, K.T., Tesfaye, Y., Dreibelbis, R., Abaire, B., Freeman, M.C., 2015. Governance and functionality of community water schemes in rural Ethiopia. Int. J. Public Health 60 (8), 977-986.

Amjad, U., Ojomo, E., Downs, K., Cronk, R., Bartram, J., 2015. Rethinking sustainability, scaling up, and enabling environment: a framework for their implementation in drinking water supply. Water 7 (4), 1497-1514.

Baumann, E., Danert, K., 2008. Operation and Maintenance of Rural Water Supplies in Malawi Study Findings (December), pp.1-60. Available at: http://www.rwsn. ch/documentation/skatdocumentation.2010-12-06.1359814977/file.

Carter, R.C., Tyrrel, S., Howsam, P., 1999. Impact and sustainability of community water supply and sanitation programmes in developing countries. J. Chart. Institution Water Environ. Manag. 13, 292-296.

da Silva, F.E., Heikkila, T., de Assis, F., de Souza, F., da Silva, D.C., 2012. Developing sustainable and replicable water supply systems in rural communities in Brazil. Int. J. Water Resour. Dev. 29 (4), 622-635.

Dayal, R., van Wijk, C., Mukherjee, N., 2000. Methodology for Participatory Assessments with Communities, Institutions and Policy Makers. Linking Sustainability with Demand, Gender and Poverty. March 2000. IRC-WSP METGUIDE.

Dube, T., 2012. Emerging issues on the sustainability of the community based rural water resources management approach in Zimbabwe: a case study of Gwanda district. Int. J. Dev. Sustain. 1 (3), 644-655.

Giné, R., Pérez Foguet, R., 2008. Sustainability assessment of national rural water supply program in Tanzania. Nat. Resour. Forum 32 (4), 327-342. Available at: http://onlinelibrary.wiley.com/doi/10.1111/j.1477-8947.2008.00213.x/full.

Harvey, P., Reed, R., 2004. Rural Water Supply in Africa: Building Blocks for Sustainability. Loughborough University, UK: Water, Engineering, and Development Centre (WEDC).

Harvey, P.A., Reed, R.A., 2006. Sustainable supply chains for rural water supplies in Africa. Proc. Institution Civ. Eng. Eng. Sustain. 159 (1), 31-39.

Haysom, A., 2006. A Study of the Factors Affecting Sustainability of Rural Water Supplies in Tanzania.

Hoko, Z., Hertle, J., 2006. An evaluation of the sustainability of a rural water rehabilitation project in Zimbabwe. Phys. Chem. Earth 31, 699-706.

Hoko, Z., Demberere, T., Siwadi, J., 2009. An evaluation of the sustainability of a water supply project in Mt Darwin district, Zimbabwe. J. Sustain. Dev. Afr. 11 (2), 98-112.

Hutton, G., Bartram, J., 2008. Regional and global costs of attaining the water supply and sanitation target (Target 10) of the millennium development goals. Bull. World Health Organ. 46045 (September 2007), 13-19.

Ihuah, P.W., Kakulu, I.I., 2014. Rural water supply projects and sustainable development in Nigeria. J. Sustain. Dev. Afr. 16 (1), 56-68.

Katz, T., Sara, J., 1997. Making Rural Water Supply Sustainable: Recommendations from a Global Study. UNDP - World Bank Water and Sanitation Program, pp. 1-8. Available at: papers2://publication/uuid/369B5C36-5FCB-482A-AA0A26C2F748COBC.

Kaliba, A.R.M., 2002. Participatory Evaluation of Community-based Water and Sanitation Programs: The Case of Central Tanzania. ProQuest Dissertations and Theses, 155-155. Available at: http://search.proquest.com/docview/305559668.

Manikutty, S., 1997. Community participation: so what? Evidence from a comparative study of two rural water supply and sanitation projects in India. Dev. Policy Rev. : J. Overseas Dev. Inst. 15 (2), 115-140.

Marks, S.J., Onda, K., Davis, J., 2013. Does sense of ownership matter for rural water system Sustainability? Evidence from Kenya. J. Water, Sanitation Hyg. Dev. 3 (2), $122-133$.

Mays, L., 2006. Water Resources Sustainability. McGraw-Hill, New York.

Montgomery, M., Bartram, J., Elimelech, M., 2009. Increasing functional sustainability of water and sanitation supplies in rural sub-Saharan Africa. Environ. Eng. Sci. 26 (5), 1017-1023.

Mwnagi, K.F., Daniel, W., 2012. An assessment of factors affecting sustainability of rural water supply schemes in Nyandarua County, Kenya: a case of Kangui Water Scheme. Int. J. Sci. Res. 3 (8), 578-584.

Panthie, K., Bhattarie, S., 2008. A Framework to Assess Sustainability of Community Based Water Projects Using Multi Criteria Analysis. Miami press, Florida International University.

Peter, G., Nkambule, S.E., 2012. Factors affecting sustainability of rural water schemes in Swaziland. Phys. Chem. Earth, Parts A/B/C 50, 196-204.

Prokopy, L.S., 2005. The relationship between participation and project outcomes: evidence from rural water supply projects in India. World Dev. 33 (11), 1801-1819. 
Quin, A., Balfors, B., Kjellen, M., 2011. How to "walk the talk". The perspectives of sector staff on implementation of rural water supply programme in Uganda. Nat. Resour. Forum 35, 269-282.

Saaty, T.L., 1980. The Analytic Hierarchy Process. McGraw-Hill International, New York, New York.

Saaty, T.L., 2008. Decision making with the analytic hierarchy process. Int. J. Serv. Sci. 1 (1), 83.

Sara, J., Katz, T., 2005. Making Rural Water Supply Sustainable, Report on the Impact of Project Rules (UNDP-world Bank Water Sanitation Programme). Available on. http://www.wsp.org (Accessed 4 July 2014).

Schouten, T., Moriarty, P., 2003. From System to Service. International Water and Sanitation Centre and ITDg, The Hague, The Netherlands.

Spaling, H., Brouwer, G., Njoka, J., 2014. Factors affecting the sustainability of a community water supply project in Kenya. Dev. Pract. 24 (7), 797-811.

Smith, G., 2011. Rural Water System Sustainability: a Case Study of CommunityManaged Water Systems in Saramaka Communities. Unpublished MSC Civil Engineering Thesis. Michigan Technological University.

Tadesse, A., Bosona, T., Gebresenbet, G., 2013. Rural water supply management and sustainability: the case of adama area, ethopia. J. Water Resour. Prot. 5 , $208-221$
U-Dominic, C.M., Ezeabasili, A.C.C., Okoro, B.U., 2015. Community-government partnership and sustainability of rural water programmes in Anambra state, Nigeria. J. Environ. Earth Sci. 4 (13), 1-13.

United Nations, 2011. The Millennium Development Goals Report 2011. Retrieved from. http://www.un.org/millenniumgoals/. Accessed 10 March 2014).

WaterAid, 2011. Sustainability Framework.

WASH Atlas, 2011. Inventory of the National Water Supply and Sanitation Facilities. WHO AND UNICEF, 2014. Progress on Drinking Water and Sanitation; 2014 Update, WHO/UNICEF Joint Monitoring Programme for Water Supply and Sanitation, United States of America.

WHO AND UNICEF, 2015. Progress on Drinking Water and Sanitation; 2015 Update, WHO/UNICEF Joint Monitoring Programme for Water Supply and Sanitation, United States of America.

Whittington, D., Davis, J., Prokopy, L., Komives, K., Thorsten, R., Lukacs, H., Bakalian, A., Wakeman, W., 2008. BWPI Working Paper 22: How Well Is the Demand-driven, Community Management Model for Rural Water Supply Systems Doing? Evidence from Bolivia, Peru, and Ghana, vol. 22. Brooks World Poverty Institute, pp. 1-26.

Zimbabwe National Statistics Agency (ZIMSTATS), 2016. Poverty Analysis - Overview (April). World Bank, pp. 1-2. 